\title{
Food Portion Patterns and Trends among U.S. Children and the Relationship to Total Eating Occasion Size, 1977-2006 ${ }^{1-3}$
}

\author{
Carmen Piernas and Barry M. Popkin* \\ Department of Nutrition, Gillings School of Global Public Health, University of North Carolina, Chapel Hill, NC 27516
}

\begin{abstract}
Food and beverage portion sizes are related to childhood obesity. We examined trends in food portion sizes and the association with total meal sizes among U.S. children. We selected children 2- to 18-y-old ( $n=31,337)$ from 4 nationally representative surveys of food intake between 1977-1978 and 2003-2006. We assessed portion sizes (kcal and g) of selected key foods (soft/fruit drinks, salty snacks, desserts, French fries, burgers, pizzas, Mexican fast foods, and hot dogs), the total energy from eating occasions that included key foods, and portion sizes of the selected key foods by source (stores, restaurants, and fast-food locations). These foods represented over one-third of children's energy intake in 2003-2006. Portion sizes increased significantly over the 30-y period and increases in pizza were particularly pronounced in the last decade [+176 kcal (736 kJ). Energy from eating occasions including pizzas and soft drinks increased, as did the proportion of energy from these foods in an eating occasion. Hamburgers and cheeseburgers increased in portion size and eating occasion size, but the proportion of these foods in the total eating occasions did not increase. Portion sizes of other key foods increased, although the total energy from eating events that included them remained constant (e.g. Mexican fast-foods, French fries, fruit drinks) or decreased (e.g. salty snacks, desserts). Portion sizes increased across all food sources (stores, restaurants, and fast foods) for soft drinks and pizzas but only at fast-food locations for French fries. Portion sizes continue to grow for selected foods. Fast-food chains appear to be linked with less healthful portion size increases for selected foods. J. Nutr. 141: 1159-1164, 2011.
\end{abstract}

\section{Introduction}

Supersizing has been suggested as one of the key factors associated with increased energy intake during a period of increased obesity among U.S. children. Major changes in eating habits have been identified during this period, including snacking and more constant eating (1-3), increased portion sizes (4-9), increased energy density of foods (10), and fast-food consumption (11-13). Scholars have thought that these factors are linked with increased childhood obesity (14-18). Of all of these factors, the supersizing of America has been the subject of most attention, yet what has been examined is the increased portion sizes of specific foods and not the total eating occasion (19).

A large body of literature suggests that increased portion size is one potential reason for increased energy intake, particularly for older children and adults $(19,20)$. One explanation is that as we age, physiological signals of hunger and satiety that self-regulate our energy intake exert less influence (17,21-23). Although

\footnotetext{
1 Supported by the University of North Carolina and the NIH (R01-CA109831 and R01-CA121152). Additional support comes from a grant from the Robert Wood Johnson Foundation.

${ }^{2}$ Author disclosures: C. Piernas and B. M. Popkin, no conflicts of interest.

${ }^{3}$ Supplemental Tables 1 and 2 are available from the "Online Supporting Material" link in the online posting of the article and from the same link in the online table of contents at jn.nutrition.org.

* To whom correspondence should be addressed. E-mail: popkin@unc.edu.
}

the critical age at which children become more susceptible to environmental exposures, such as bigger portions, remains unclear, research suggests that children of all ages are predisposed to overeat (24-26).

Trends in the portion sizes of foods commonly eaten in the United States are not available for children, because the literature has either focused on portion size offerings (4-7) or the portion sizes consumed by adults $(8,27)$. Other research has shown increased energy intakes for all age groups, particularly consumption of salty snacks, soft drinks, burgers, French fries, and Mexican fast foods (8). This study focuses on nationally representative surveys of food intake in the United States. We present updated trends in overall portion sizes ( $\mathrm{kcal}$ and $\mathrm{g}$ ) among U.S. children (2-18 y old) from 1977-1978 to 2003-2006. We add new insights by studying portion sizes of selected key foods within eating occasions that include those key foods. We provide further understanding by examining trends in energy density of key foods and portion sizes by location of food source.

\section{Participants and Methods}

Participants and study design. A total of 31,337 children and adolescents 2-18 y old were selected from 4 nationally representative USDA surveys of food intake among the U.S. population. The participants included children from the USDA Nationwide Food Consumption Survey 
in 1977-1978 (NFCS $1977-78 ;{ }^{4} n=12,231$ ) (28), the USDA Continuing Survey of Food Intake by Individuals in 1989-1991 (CSFII 1989-91; $n=$ 3148) (29), the USDA Continuing Survey of Food Intake by Individuals in 1994-1996 and 1998 (CSFII 1994-98; $n=8621$ ) (30), and the pooled NHANES 2003-2004 and 2005-2006 (NHANES 2003-06; $n=7337$ ) $(31,32)$.

These surveys are based on a multistage and stratified area probability sample of noninstitutionalized U.S. households. NHANES used sampling designs, survey instruments, dietary collection methods, and food composition tables that were designed to match earlier procedures of NFCS and CSFII. Detailed information about each survey has been previously published (28-32). Our study was exempt from institutional review by utilizing secondary USDA and NHANES data.

Dietary data. The NFCS 1977-78 and the CSFII 1989-91 recorded dietary intake on 3 consecutive days. A single interviewer administered a 24 -h recall and collected $2 \mathrm{~d}$ of self-administered food records. The CSFII 1994-98 and the NHANES 2003-06 collected 2 nonconsecutive days using interviewer-administered 24-h recalls (3-10 d apart). For children $<12$ y old, dietary information was obtained from the child's caregiver. To provide comparable data and also expand the number of eating occasions that included one of the selected foods, the first $2 \mathrm{~d}$ of dietary intake from each survey were included in the present analysis.

Eating occasions and portion size measurements. Eating occasions are defined as a combination of self-reported breakfast/brunch, lunch and dinner/supper, and snacking occasions $(1,2)$. Items consumed within a 15 -min period were combined as a single eating occasion. Self-defined "snack" items consumed within a meal were considered as part of that meal (e.g. chips within a lunch).

For each food consumed, the respondents were also asked where the food was obtained. This information was used to study 3 food sources: stores, restaurants, and fast-food locations. Soft drinks, French fries, and pizzas were the key foods selected to study the changes of portion sizes over time by source. For other key foods, the sample size was not large enough to allow analysis by source.

Portion sizes were calculated as the amount of food (kcal and g) consumed at a given eating occasion. The USDA/NHANES surveys used food models to assist respondents in identifying the portion size. To show trends over time for overall portion sizes, per-consumer means were calculated over a 2-d period. Per-consumer means are intended to show changes in the average portion size for those individuals consuming a specific item. To study trends over time for portion sizes and eating occasions, the sample unit used was the eating occasion with the selected food or beverage. A person could consume the same key food 2 or more times during the $2 \mathrm{~d}$ recalled and almost all portions were based on 1 or 2 eating events/child. The number of eating occasions on $\mathrm{d} 1$ or 2 or both was used to calculate portion sizes of selected key foods within eating occasions that included those foods. We report portion sizes means (kcal and $\mathrm{g}$ or $\mathrm{mL}$ ) for each key food and for the whole eating occasion that includes a key food (e.g. we calculated the mean portion size for all pizzas and the mean portion size of all eating events containing pizza). Similarly, we calculated the energy density $(\mathrm{kcal} / \mathrm{g})$ of selected key foods and the eating occasions containing those key foods dividing the energy ( $\mathrm{kcal}$ ) by the grams consumed.

Key foods and food grouping system. Food portion sizes were studied for these selected key foods: salty snacks, desserts, soft drinks, fruit drinks, French fries, hamburgers, cheeseburgers, pizzas, Mexican fast foods, and hot dogs. Salty snacks included crackers, chips, pretzels, rice cakes, and popcorn. Desserts included ice creams, pies, cakes, and cookies. Soft drinks and fruit drinks included caloric sweetened beverages and did not include diet drinks or $100 \%$ fruit juice. Hamburgers and cheeseburgers consisted of items served from typical menus at fast-food chains. Mexican fast foods included burritos, enchiladas, tacos, and similar items.

\footnotetext{
${ }^{4}$ Abbreviations used: CSFII 1989-91, USDA Continuing Survey of Food Intake by Individuals in 1989-1991; NFCS 1977-78, Nationwide Food Consumption Survey in 1977-1978; NHANES 2003-06, pooled NHANES 2003-04 and 2005-06.
}

The selected key foods had the greatest increase in terms of energy among Americans $>2$ y old between 1977 and $1996(33,34)$. To create the different key food categories, we used the University of North Carolina food grouping system, which was previously described $(8,34,35)$.

Statistical analysis. All analyses were performed with STATA 11 (36). We used survey commands (SVY: MEAN) to account for survey design, weighting, and clustering. Data are reported as means \pm SE. For each year surveyed, we calculated overall portion sizes ( $\mathrm{kcal}$ and $\mathrm{g}$ ), portion sizes of key foods ( $\mathrm{kcal})$, and portion sizes of eating occasions including those key foods (kcal). We also determined the energy density of key foods and eating occasions including those key foods (kcal/g). For selected key foods, we studied changes in portion sizes over time by source (stores, restaurants, fast-food locations). Differences testing based on the Student's $t$ test with a post hoc Bonferroni's test used TEST and MTEST (B) commands after SVY: MEAN commands on STATA 11 (36). A 2-sided $P$-value $<0.01$ was set for significance.

\section{Results}

Energy intake and key food consumption. The socioeconomic characteristics of respondents are presented in Table 1. Daily energy intake increased significantly by $\sim 184 \mathrm{kcal}$ among U.S. children between 1977-1978 and 2003-2006. We found that the key foods studied have become increasingly popular among children 2-18 y old, accounting to more than one-third of the total energy intake in 2003-2006 (Table 1).

Trends in overall portion sizes. Portion sizes (kcal/portion) of all key foods studied increased significantly between 1977-1978 and 2003-2006 with the exception of desserts, which remained unchanged (Fig. 1). Pizzas and Mexican fast foods accounted for the greatest increases in energy intake among all the key foods (131 and $150 \mathrm{kcal} /$ portion, respectively). Pizzas and Mexican fast foods together with hamburgers and cheeseburgers were the foods with the highest mean energy per portion in 2003-2006. In the past decade, pizzas were the key food with the largest energy increase (+172 kcal/portion from 1994-1998 to 2003-2006).

Portion size $(\mathrm{g}, \mathrm{oz}, \mathrm{mL})$, rather than kcal, provides a different perspective. Increases in the portions of soft drinks and fruit drinks were highly remarkable in terms of $\mathrm{mL} /$ portion (Supplemental Table 1). Soft drinks increased $\sim 100 \mathrm{~mL}$ between $1977-$ 1978 and 2003-2006, and fruit drinks increased $\sim 43 \mathrm{~mL}$ in the same period. Grams per portion consumed of the other key foods also increased significantly over the 30 -y period: $31 \mathrm{~g}$ more for hamburgers, $22 \mathrm{~g}$ more for cheeseburgers, $41 \mathrm{~g}$ more for pizzas, and $48 \mathrm{~g}$ more for Mexican fast foods (Supplemental Table 1).

\section{Trends in portion sizes within eating occasions.} Increased portion sizes of key foods and total energy intake from eating occasions. From 1977-1978 to 2003-2006, pizza, soft drinks, hamburgers, and cheeseburgers increased in portion size (kcal). Total energy from eating occasions containing those items also increased during the same period (Table 2). The percentage of energy intake from pizzas and soft drinks in the total energy intake from an eating occasion increased, suggesting that portion size increases of pizzas and soft drinks are directly responsible for increases in energy intake from eating occasions including them. For pizzas, the increases in the last decade were more important than the long-term changes $(+178 \mathrm{kcal}$ from 1994 to 2006 vs. $+140 \mathrm{kcal}$ from 1977 to 2006 ), as were the increases in total energy for eating occasions containing pizza $(+188 \mathrm{kcal}$ from 1994 to 2006 vs. $+126 \mathrm{kcal}$ from 1977 to 2006). Although energy from eating occasions containing hamburgers and cheeseburgers accounted for the highest mean energy per eating occasion in 
TABLE 1 Characteristics of U.S. children 2-18 y old (1977-2006) from 4 nationally representative surveys ${ }^{1}$

\begin{tabular}{|c|c|c|c|c|}
\hline & NFCS 1977-78 & CSFII 1989-91 & CSFII 1994-98 & NHANES 2003-06 \\
\hline Participants, $n$ & 12,231 & 3148 & 8621 & 7337 \\
\hline \multicolumn{5}{|l|}{ Eating occasions, $n$} \\
\hline d 1 & 46,687 & 15,203 & 44,496 & 38,100 \\
\hline d 2 & 45,349 & 12,585 & 40,424 & 32,069 \\
\hline \multicolumn{5}{|l|}{ Gender, \% } \\
\hline Males & $49.8^{\mathrm{a}}$ & $50.4^{\mathrm{a}}$ & $51.1^{\mathrm{a}}$ & $50.6^{\mathrm{a}}$ \\
\hline Females & $50.2^{\mathrm{a}}$ & $49.6^{\mathrm{a}}$ & $48.9^{\mathrm{a}}$ & $49.4^{\mathrm{a}}$ \\
\hline \multicolumn{5}{|l|}{ Ethnicity, ${ }^{2} \%$} \\
\hline White, non-Hispanic & $78.7^{\mathrm{a}}$ & $72.1^{\mathrm{ab}}$ & $65.2^{\mathrm{bc}}$ & $61.1^{\mathrm{c}}$ \\
\hline Black, non-Hispanic & $16.0^{\mathrm{a}}$ & $15.2^{\mathrm{a}}$ & $15.9^{\mathrm{a}}$ & $14.6^{\mathrm{a}}$ \\
\hline Hispanic & $4.15^{\mathrm{c}}$ & $10.2^{b}$ & $14.0^{\mathrm{ab}}$ & $17.5^{\mathrm{a}}$ \\
\hline \multicolumn{5}{|l|}{ National poverty level, \% } \\
\hline$<130 \%$ & $25.0^{\mathrm{ab}}$ & $24.5^{\mathrm{b}}$ & $26.3^{\mathrm{ab}}$ & $29.8^{\mathrm{a}}$ \\
\hline $130 \%-300 \%$ & $44.4^{\mathrm{a}}$ & $35.7^{\mathrm{bc}}$ & $39.0^{\mathrm{b}}$ & $31.3^{\mathrm{c}}$ \\
\hline$>300 \%$ & $30.5^{b}$ & $39.8^{\mathrm{a}}$ & $34.7^{\mathrm{ab}}$ & $38.8^{\mathrm{a}}$ \\
\hline \multicolumn{5}{|l|}{ Household education, \% } \\
\hline$<$ High school diploma & $73.0^{\mathrm{a}}$ & $62.7^{\mathrm{b}}$ & $52.1^{c}$ & $45.3^{d}$ \\
\hline$\geq$ High school diploma & $27.0^{\mathrm{d}}$ & $37.3^{\mathrm{c}}$ & $47.9^{b}$ & $54.7^{\mathrm{a}}$ \\
\hline Total energy intake, ${ }^{3} \mathrm{kcal} / \mathrm{d}$ & $1839 \pm 14^{b}$ & $1765 \pm 27^{b}$ & $1954 \pm 23^{\mathrm{a}}$ & $2023 \pm 15^{\mathrm{a}}$ \\
\hline Energy from all key foods ${ }^{2} \%$ energy & $23.7^{d}$ & $29.5^{c}$ & $33.7^{\mathrm{b}}$ & $36.2^{\mathrm{a}}$ \\
\hline Salty snacks & $2.19^{d}$ & $3.61^{\mathrm{c}}$ & $4.96^{b}$ & $5.91^{\mathrm{a}}$ \\
\hline Desserts & $9.60^{\mathrm{a}}$ & $8.76^{\mathrm{a}}$ & $9.48^{\mathrm{a}}$ & $9.10^{\mathrm{a}}$ \\
\hline Soft drinks & $3.12^{\mathrm{c}}$ & $3.98^{\mathrm{b}}$ & $5.20^{\mathrm{a}}$ & $4.99^{\mathrm{a}}$ \\
\hline French fries & $1.80^{\mathrm{b}}$ & $2.41^{\mathrm{a}}$ & $2.64^{\mathrm{a}}$ & $2.31^{\mathrm{a}}$ \\
\hline Hamburgers/cheeseburgers & $1.06^{\mathrm{b}}$ & $1.94^{\mathrm{a}}$ & $1.78^{\mathrm{a}}$ & $1.55^{\mathrm{a}}$ \\
\hline Pizzas & $1.35^{\mathrm{c}}$ & $3.51^{b}$ & $3.45^{\mathrm{b}}$ & $5.54^{\mathrm{a}}$ \\
\hline Mexican fast foods & $0.35^{\mathrm{c}}$ & $1.13^{\mathrm{b}}$ & $1.32^{\mathrm{b}}$ & $2.01^{\mathrm{a}}$ \\
\hline
\end{tabular}

${ }^{1}$ Values are means \pm SE or percentage. Values in a row without a common letter differ, $P<0.01$

${ }^{2}$ Subcategories of ethnicity and key foods do not sum to $100 \%$, because the remaining percentage from other ethnicities and key foods is hidden.

${ }^{3} 1 \mathrm{kcal}=4.19 \mathrm{~kJ}$.

2003-2006 (862 kcal for hamburgers and $887 \mathrm{kcal}$ for cheeseburgers), the proportion of energy from a portion of hamburger or cheeseburger that accounts to the total energy of that meal did not increase, indicating that the changes in total energy intake of the eating event are not only attributable to increases in energy intake from burgers but also could be driven by increases in other items

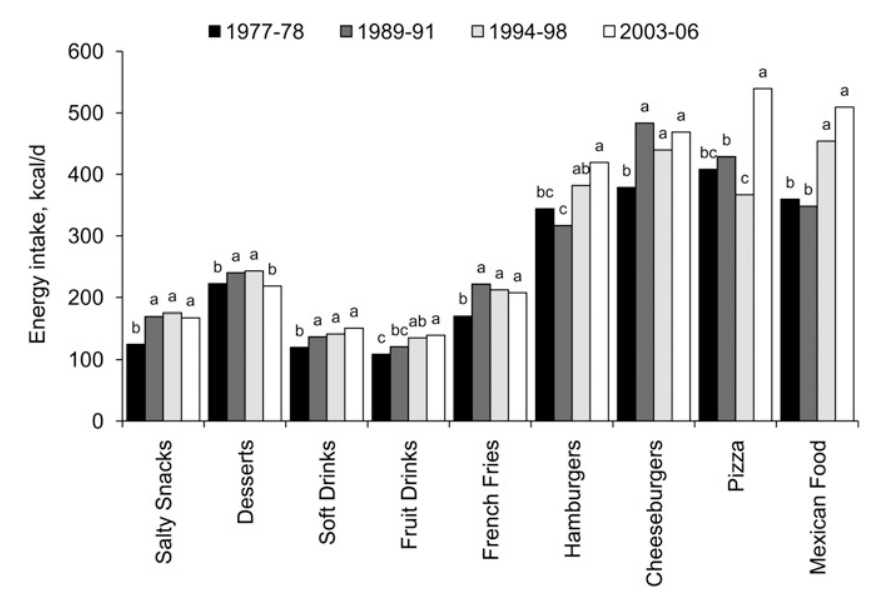

FIGURE 1 Trends in overall portion sizes (kcal) in U.S. children 2-18 y old (1977- 2006). The sample included respondents $2-18$ y old from 4 nationally representative surveys: NFCS 1977-78 ( $n=12,231)$, CSFII 1989-91 $(n=3148)$, CSFII 1994-98 $(n=8621)$, and NHANES 2003-06 $(n=$ 7337). Means without a common letter differ, $P<0.01 .1 \mathrm{kcal}=4.19 \mathrm{~kJ}$. included in that meal (e.g. French fries or soft drinks) (Supplemental Table 2).

Increased portion sizes of key foods but unchanged/ decreased total energy intake from eating occasions. Increases in portion sizes (kcal) of Mexican fast foods, French fries, and fruit drinks did not coincide with significant increases in total energy intake from eating events containing them. For the eating occasions linked with salty snacks, hot dogs, and desserts, the energy intake of the eating occasion actually decreased. Although the proportion of energy from key foods that accounts for the total energy from eating events increased, the portion size increases reported for these items were not responsible for the increases in energy intake from eating occasions including them.

Trends in energy density of key foods and eating occasions. Increases in the energy density of the key foods were significant for salty snacks, fruit drinks, French fries, hamburgers, cheeseburgers, pizzas, and Mexican fast foods (Table 3). For the same period (1977-1978 to 2003-2006), soft drink and hot dog energy densities significantly decreased. Energy densities for eating occasions including salty snacks, desserts, hamburgers, cheeseburgers, pizzas, Mexican fast foods, and hot dogs also significantly increased between 1977-1978 and 2003-2006.

Trends in portion sizes of key foods by source. To further understand if portion sizes are influenced by source, changes over time were studied for soft drinks, French fries, and pizzas (Fig. 2). 
TABLE 2 Changes in portion sizes of key foods and eating occasions in U.S. children 2-18 y old between 1977-1978 and $2003-2006^{1-3}$

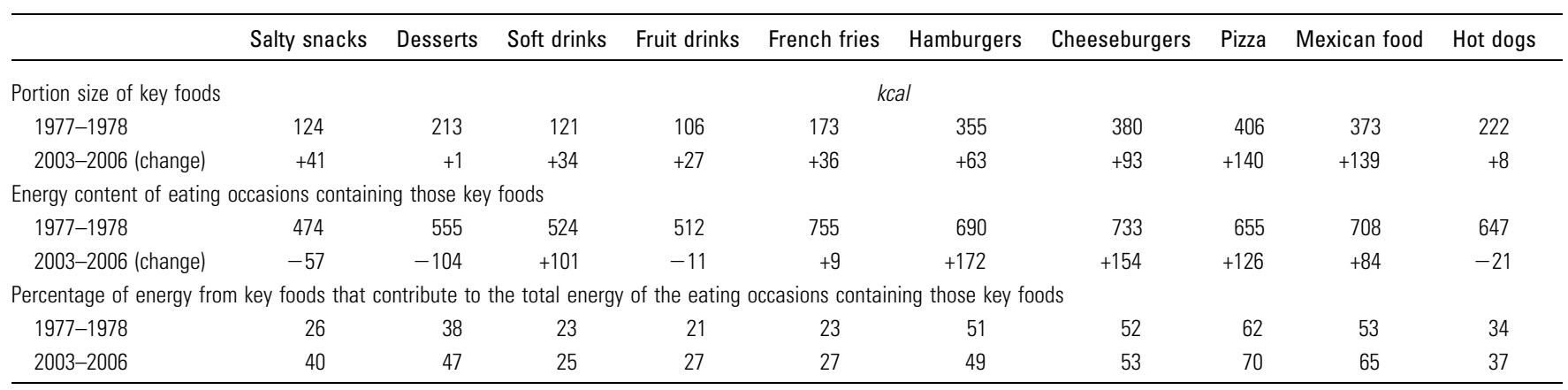

1 The analysis sample included respondents aged 2-18 y old from 4 nationally representative surveys: NFCS 1977-78 ( $n=12231$ ), CSFII 1989-91 ( $n=3148$ ), CSFII 1994-98 ( $n=8621)$, and NHANES 2003-06 $(n=7337)$. Weighted to be nationally representative.

$21 \mathrm{kcal}=4.19 \mathrm{~kJ}$.

${ }^{3}$ The $\%$ energy was calculated by dividing: (kcal from key foods)/(kcal from eating occasions containing those key foods) $\times 100$.

Energy intake from soft drinks purchased in stores, restaurants, and fast-food restaurants significantly increased from 1977-1978 to 2003-2006, with increases in restaurants and fast-food restaurants being greater than in stores. Portion sizes of French fries increased significantly only in fast-food restaurants, whereas they decreased in stores and remained unchanged in restaurants. Portion sizes of pizzas significantly increased for stores and fastfood restaurants over the same period. Fast-food chains accounted for the highest increase in energy from pizza (Fig. 2).

\section{Discussion}

Over the past 3 decades, the total energy intake of U.S. children $2-18$ y old has increased by $\sim 184 \mathrm{kcal} / \mathrm{d}$. The selected foods we studied (soft drinks, fruit drinks, desserts, French fries, burgers, pizzas, Mexican fast foods, and hot dogs) represent $\sim 36 \%$ of the daily energy intake of U.S. children. Overall, portion sizes for all of these foods increased over the period studied. The significant increases in portion sizes of pizza $(+131 \mathrm{kcal} / \mathrm{d})$, hamburgers $(+90$ $\mathrm{kcal} / \mathrm{d})$, cheeseburgers (+90 kcal/d), and Mexican fast food (+149 $\mathrm{kcal} / \mathrm{d}$ ) are remarkable in the past 3 decades.

Portion sizes of these selected foods are important for energy regulation when the total energy content of the eating occasions including these foods also increases. This study examined this topic. Portion sizes of pizza and soft drinks increased simultaneously with increased energy of the eating occasions containing those foods. At the same time, the proportion of energy intake from those key foods for a respective eating occasion also increased. For burgers (hamburgers and cheeseburgers), portion sizes and total energy from its respective eating occasion increased. However, the proportion of energy from a portion size of a burger that comprises the total energy content of an eating occasion did not increase, suggesting that those items were not directly responsible for the changes in total energy of eating events. Portion sizes of other key foods increased, although the total energy intake from eating events including them remained unchanged (e.g. Mexican fast foods, French fries, and fruit drinks) or even decreased (e.g. salty snacks and desserts).

Larger portions of foods and sweetened beverages commonly consumed in the US have been previously studied both in terms of actual food consumed and food portions offered. In terms of consumption, most research has been focused on either adults or on all Americans $>2$ y old for earlier time periods (8). Among 6- to $17-y$ olds, increased prevalence of soft drink consumption and larger portion sizes of soft drinks were previously reported

TABLE 3 Trends in energy density of key foods and eating occasions including those key foods by U.S. children $2-18$ y old (1977-2006) from 4 nationally representative surveys ${ }^{1,2}$

\begin{tabular}{|c|c|c|c|c|c|c|c|c|}
\hline \multirow[b]{3}{*}{ Key foods } & \multicolumn{4}{|c|}{ Energy density of key foods } & \multicolumn{4}{|c|}{ Energy density of eating occasions } \\
\hline & NFCS & CSFII & CSFII & NHANES & NFCS & CSFII & CSFII & NHANES \\
\hline & 1977-78 & $1989-91$ & 1994-98 & $2003-06$ & 1977-78 & 1989-91 & 1994-98 & $2003-06$ \\
\hline Salty snacks & $4.92 \pm 0.01^{\mathrm{ab}}$ & $4.87 \pm 0.03^{b}$ & $4.88 \pm 0.01^{b}$ & $4.97 \pm 0.01^{\mathrm{a}}$ & $1.86 \pm 0.03^{b}$ & $2.22 \pm 0.11^{\mathrm{a}}$ & $2.43 \pm 0.03^{\mathrm{a}}$ & $2.45 \pm 0.04^{\mathrm{a}}$ \\
\hline Desserts & $3.17 \pm 0.02^{\mathrm{a}}$ & $3.15 \pm 0.08^{\mathrm{a}}$ & $3.23 \pm 0.03^{\mathrm{a}}$ & $3.25 \pm 0.03^{\mathrm{a}}$ & $1.69 \pm 0.01^{b}$ & $1.89 \pm 0.06^{\mathrm{a}}$ & $2.03 \pm 0.02^{\mathrm{a}}$ & $1.96 \pm 0.03^{\mathrm{a}}$ \\
\hline Soft drinks & $0.41 \pm 0.00^{\mathrm{a}}$ & $0.41 \pm 0.00^{\mathrm{a}}$ & $0.41 \pm 0.00^{\mathrm{a}}$ & $0.39 \pm 0.00^{\mathrm{b}}$ & $1.01 \pm 0.01^{\mathrm{a}}$ & $1.03 \pm 0.01^{\mathrm{a}}$ & $0.97 \pm 0.01^{b}$ & $0.97 \pm 0.01^{b}$ \\
\hline French fries & $2.54 \pm 0.02^{\mathrm{c}}$ & $2.80 \pm 0.02^{b}$ & $2.79 \pm 0.02^{b}$ & $2.88 \pm 0.02^{\mathrm{a}}$ & $1.44 \pm 0.01^{b}$ & $1.53 \pm 0.03^{\mathrm{a}}$ & $1.49 \pm 0.02^{\mathrm{a}}$ & $1.46 \pm 0.02^{\mathrm{ab}}$ \\
\hline Hamburgers & $2.42 \pm 0.01^{b}$ & $2.51 \pm 0.02^{\mathrm{ab}}$ & $2.51 \pm 0.01^{\mathrm{ab}}$ & $2.61 \pm 0.01^{\mathrm{a}}$ & $1.38 \pm 0.01^{c}$ & $1.45 \pm 0.02^{\mathrm{bc}}$ & $1.48 \pm 0.02^{\mathrm{ab}}$ & $1.54 \pm 0.03^{\mathrm{a}}$ \\
\hline Cheeseburgers & $2.45 \pm 0.01^{c}$ & $2.60 \pm 0.03^{\mathrm{ab}}$ & $2.53 \pm 0.01^{b}$ & $2.66 \pm 0.01^{\mathrm{a}}$ & $1.37 \pm 0.03^{b}$ & $1.52 \pm 0.04^{\mathrm{a}}$ & $1.47 \pm 0.03^{\mathrm{ab}}$ & $1.55 \pm 0.04^{\mathrm{a}}$ \\
\hline Pizzas & $2.75 \pm 0.01^{c}$ & $2.79 \pm 0.01^{b}$ & $2.82 \pm 0.01^{b}$ & $2.88 \pm 0.01^{\mathrm{a}}$ & $1.43 \pm 0.02^{b c}$ & $1.42 \pm 0.04^{\mathrm{C}}$ & $1.54 \pm 0.03^{b}$ & $1.64 \pm 0.03^{\mathrm{a}}$ \\
\hline Mexican fast foods & $2.29 \pm 0.02^{b}$ & $2.34 \pm 0.09^{a b}$ & $2.50 \pm 0.03^{\mathrm{a}}$ & $2.50 \pm 0.03^{\mathrm{a}}$ & $1.30 \pm 0.04^{b}$ & $1.40 \pm 0.07^{\mathrm{ab}}$ & $1.55 \pm 0.03^{\mathrm{a}}$ & $1.44 \pm 0.03^{\mathrm{a}}$ \\
\hline Hot dogs & $3.39 \pm 0.01^{\mathrm{a}}$ & $3.33 \pm 0.05^{\mathrm{ab}}$ & $3.19 \pm 0.02^{c}$ & $3.23 \pm 0.01^{\mathrm{bc}}$ & $1.46 \pm 0.01^{b}$ & $1.54 \pm 0.04^{\mathrm{ab}}$ & $1.59 \pm 0.02^{\mathrm{a}}$ & $1.55 \pm 0.02^{\mathrm{a}}$ \\
\hline
\end{tabular}

${ }^{1}$ Values are \pm SE, $n=12,231$ (NFCS 1977-78), 3148 (CSFII 1989-91) 8621 (CSFII 1994-98), or 7337 (NHANES 2003-06). Means for a variable in a row without a common letter differ, $P<0.01$

$21 \mathrm{kcal}=4.19 \mathrm{~kJ}$. 


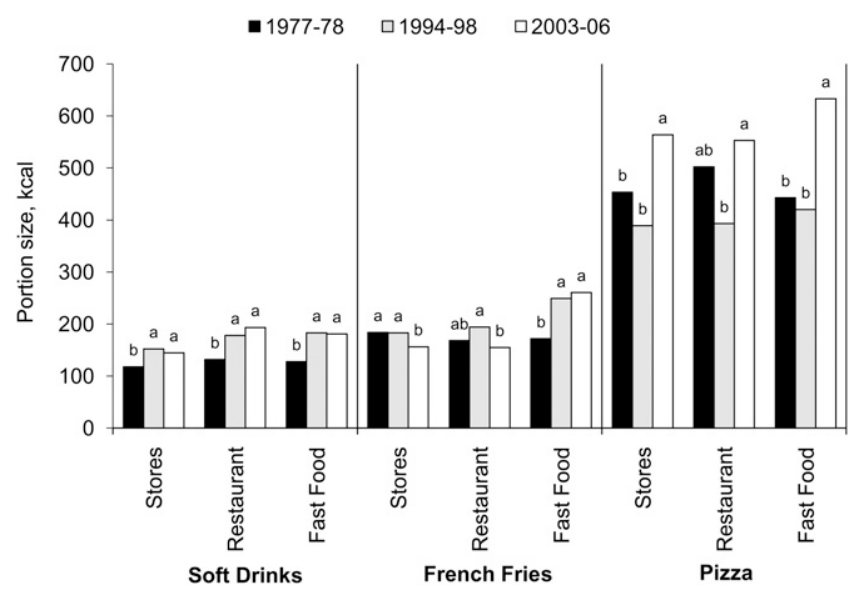

FIGURE 2 Trends in food portion sizes (kcal) for selected key foods in U.S. children 2-18 y old (1977-2006). The sample included respondents $2-18$ y old from 4 nationally representative surveys: NFCS 1977-78 $(n=12,231)$, CSFII 1989-91 $(n=3148)$, CSFII 1994-98 $(n=$ 8621), and NHANES 2003-06 $(n=7337)$. Means without a common letter differ, $P<0.01$.

(37). In terms of portion sizes offerings, other scholars have shown similar significant increases for most of the foods found in fast-food locations and elsewhere in some cases $(4,6,7)$.

Interestingly, portion sizes of French fries significantly increased only at fast-food places, whereas portion sizes of pizza increased at stores and fast-food places and soft drinks increased at all 3 food sources. Larger portion sizes are specially appreciated by costumers who can get more food for only a small additional cost or even at no cost. Because people usually eat what is served rather than what is adequate for their energy needs, value meals have been found to promote overeating at restaurants (38). On the other hand, higher price indices of fast foods have been positively associated with healthier eating patterns and overall diet quality (increased intake of fiber, calcium, fruit, vegetables, and dairy) among 2- to 9-y olds (39).

The nutritional implications of larger portions and the subsequent effects on increased energy intake have been ignored in previous research. Increases in overall portions of individual foods are not enough by themselves to explain the increases in the overall energy intake, and the processes of hunger-satiety and self-regulation must be taken into account (40-43). Extensive research has shown that increased portion sizes at an eating occasion can be linked with increased total energy intake (4446). However, this research has led to the confusion that an increase in the portion size of any selected food can increase the overall portion size of the eating occasion (13). One short-term study linked larger portion sizes of selected key foods with increased energy intake at an eating occasion (38). We showed that increased portion sizes ( $\mathrm{kcal}$ ) of soft drinks and pizzas were associated with significant increases in energy intake from eating occasions that include those foods. In contrast, increased portion sizes did not influence the energy content of eating occasions containing other key foods, such as Mexican fast food, French fries, fruit drinks, salty snacks, and desserts.

There are important limitations to note. The methodologies used to collect 24-h recall data have been adapted in surveys between 1994 and the present to improve recall and reduce bias. However, there is no bridging study, as one done between the 1970s and 1980s (47), to allow us to understand any of the methodological changes and if they could affect either total energy intake or foods measured. There are other problems associated with measuring the usual intake with data from 1 to $2 \mathrm{~d}$ of self-reported dietary intake per day, and our results most likely are affected by underreporting (48). On the other hand, the accuracy of estimation of large portions decreases systematically (49) and when familiar food models are used (50). Furthermore, people tend to underreport unhealthy foods, especially when those foods relate to obesity (51). Among children, underreporting increases with age, and ethnic and gender differences are also important sources of differential underreporting (52). Another study showed that overweight and obese children also tend to underreport their diet (53).

Other problematic issues such as the differential recall of mixed dishes or recipes (e.g. hamburgers or pizza) could also affect our results. Sometimes, these items are directly reported by the respondents, whereas other times, respondents might report each food item separately (e.g. bread, beef, tomato), therefore making it difficult to know if they consumed a hamburger or 2 separate foods in 1 eating occasion. In the present study, this issue was particularly frequent for hamburgers and cheeseburgers obtained in restaurants and at home. We concluded from the data that hamburgers and cheeseburgers were always recorded as such when purchased from fast-food eateries. In contrast, this was not systematically done for these same items consumed at a restaurant or coming from stores and eaten at home, which were probably recalled as individual food items.

Our data support the general consensus that portion sizes are increasing and in selected cases appear to be potentially important sources of increased eating occasion energy intake among children in the United States. Using nationally representative data on food intake, we have presented patterns and trends in portion sizes of foods commonly eaten by U.S. children. This study identified some key foods, such as soft drinks and pizzas, as potential contributors to the increased energy intake at eating occasions. Portion size increases in pizzas in the last decade were particularly large. These results also provide some perspective on many situations where the increased portion size of a selected food is only linked to an increased portion of that food (e.g. salty snacks, desserts, Mexican fast foods) but not to the total energy intake from the eating occasion. These results suggest that nutrition education and other programmatic and policy initiatives should look specifically at selected foods, such as pizzas and soft drinks, that are particularly common among children and adolescents in the United States and that could increase the intake of energy, fats, and added sugars.

\section{Acknowledgments}

We thank Phil Bardsley for programming help, Tom Swasey for graphic assistance, and Frances Dancy for administrative support. C.P. and B.M.P. had full access to all study data and take full responsibility for the integrity of the data and accuracy of the analysis; B.M.P. designed the research (study concept and design, critical revision of the manuscript for important intellectual content), obtained funding, and supervised the study; and B.M.P. and C.P. conducted the research, analyzed the data, wrote the paper, and provided administrative, technical, or material support. Both authors read and approved the final manuscript.

\section{Literature Cited}

1. Duffey KJ, Gordon-Larsen P, Shikany JM, Guilkey D, Jacobs DR Jr, Popkin BM. Food price and diet and health outcomes: 20 years of the CARDIA Study. Arch Intern Med. 2010;170:420-6.

2. Piernas C, Popkin BM. Trends in snacking among U.S. children. Health Aff (Millwood). 2010;29:398-404.

3. Piernas C, Popkin BM. Snacking increased among U.S. adults between 1977 and 2006. J Nutr. 2010;140:325-32. 
4. Duffey KJ, Gordon-Larsen P, Jacobs DR Jr, Williams OD, Popkin BM. Differential associations of fast food and restaurant food consumption with 3-y change in body mass index: the Coronary Artery Risk Development in Young Adults Study. Am J Clin Nutr. 2007;85:201-8.

5. Popkin BM, Duffey KJ. Does hunger and satiety drive eating anymore? Increasing eating occasions and decreasing time between eating occasions in the United States. Am J Clin Nutr. 2010;91:1342-7.

6. Ogden CL, Carroll MD, Curtin LR, Lamb MM, Flegal KM. Prevalence of high body mass index in US children and adolescents, 2007-2008. JAMA. 2010;303:242-9.

7. Francis LA, Lee Y, Birch LL. Parental weight status and girls' television viewing, snacking, and body mass indexes. Obes Res. 2003;11:143-51.

8. Nielsen SJ, Popkin BM. Patterns and trends in food portion sizes, 19771998. JAMA. 2003;289:450-3.

9. Smiciklas-Wright H, Mitchell DC, Mickle SJ, Goldman JD, Cook A. Foods commonly eaten in the United States, 1989-1991 and 19941996: are portion sizes changing? J Am Diet Assoc. 2003;103:41-7.

10. Ledikwe JH, Blanck HM, Khan LK, Serdula MK, Seymour JD, Tohill BC, Rolls BJ. Dietary energy density determined by eight calculation methods in a nationally representative United States population. J Nutr. 2005;135:273-8.

11. Soderlund C, Descour A, Kudrna D, Bomhoff M, Boyd L, Currie J, Angelova A, Collura K, Wissotski M, et al. Sequencing, mapping, and analysis of 27,455 maize full-length cDNAs. PLoS Genet. 2009;5:e1000740.

12. Stender S, Dyerberg J, Astrup A. Fast food: unfriendly and unhealthy. Int J Obes (Lond). 2007;31:887-90.

13. Spurlock M. Don't eat this book: fast food and the supersizing of America. New York: G.P. Putnam's Sons; 2005.

14. Kral TV, Rolls BJ. Energy density and portion size: their independent and combined effects on energy intake. Physiol Behav. 2004;82:131-8.

15. Flegal KM, Carroll MD, Ogden CL, Curtin LR. Prevalence and trends in obesity among US adults, 1999-2008. JAMA. 2010;303:235-41.

16. Young LR, Nestle M. The contribution of expanding portion sizes to the US obesity epidemic. Am J Public Health. 2002;92:246-9.

17. McConahy KL, Smiciklas-Wright H, Birch LL, Mitchell DC, Picciano MF. Food portions are positively related to energy intake and body weight in early childhood. J Pediatr. 2002;140:340-7.

18. Ogden CL, Flegal KM, Carroll MD, Johnson CL. Prevalence and trends in overweight among US children and adolescents, 1999-2000. JAMA. 2002;288:1728-32.

19. Orlet Fisher J, Rolls BJ, Birch LL. Children's bite size and intake of an entree are greater with large portions than with age-appropriate or selfselected portions. Am J Clin Nutr. 2003;77:1164-70.

20. Rolls BJ, Engell D, Birch LL. Serving portion size influences 5-year-old but not 3-year-old children's food intakes. J Am Diet Assoc. 2000;100:232-4.

21. Birch LL, Deysher M. Caloric compensation and sensory specific satiety: evidence for self regulation of food intake by young children. Appetite. 1986;7:323-31.

22. Birch LL, Fisher JO, Davison KK. Learning to overeat: maternal use of restrictive feeding practices promotes girls' eating in the absence of hunger. Am J Clin Nutr. 2003;78:215-20.

23. Fisher JO. Effects of age on children's intake of large and self-selected food portions. Obesity (Silver Spring). 2007;15:403-12.

24. French SA, Story M, Jeffery RW. Environmental influences on eating and physical activity. Annu Rev Public Health. 2001;22:309-35.

25. Birch LL, Fisher JO. Development of eating behaviors among children and adolescents. Pediatrics. 1998;101:539-49.

26. Harnack LJ, Jeffery RW, Boutelle KN. Temporal trends in energy intake in the United States: an ecologic perspective. Am J Clin Nutr. 2000;71:1478-84.

27. Nielsen SJ, Siega-Riz AM, Popkin BM. Trends in energy intake in U.S. between 1977 and 1996: similar shifts seen across age groups. Obes Res. 2002;10:370-8.

28. Rizek R. The 1977-78 Nationwide Food Consumption Survey. Fam Econ Rev. 1978;4:3-7.

29. U.S. Department of Agriculture ARS, Beltsville Human Nutrition Research Center, Food Surveys Research Group. Beltsville, MD. Continuing Survey of Food Intakes by Individuals 1989-91 and Diet and Health Knowledge Survey 1989-91: documentation (csfii8991_ documentation.pdf) [cited 2009 May 6]. Available from: http://www. ars. usda.gov/Services/docs.htm? docid=14541.

30. USDA Agricultural Research Service, Food Surveys Research Group Web site. Beltsville, MD: U.S. Department of Agriculture ARS, Beltsville
Human Nutrition Research Center, Food Surveys Research Group. Continuing Survey of Food Intakes by Individuals 1994-96, 1998 and Diet and Health Knowledge Survey 1994-96: documentation (csfii9498_ documentationupdated.pdf) [cited 2009 May 6]. Available from: http:// www.ars.usda.gov/Services/docs.htm?docid=14521.

31. USDA Agricultural Research Service, Food Surveys Research Group Web site. Beltsville, MD: U.S. Department of Agriculture ARS, Beltsville Human Nutrition Research Center, Food Surveys Research Group and Hyattsville, MD: U.S. Department of Health and Human Services CfDCaP, National Center for Health Statistics. What We Eat in America, NHANES 2005-2006 [cited 200930 Jul]. Available from: http://www. cdc.gov/nchs/about/major/nhanes/nhanes2005-2006/dr1tot_c.xpt.

32. U USDA Agricultural Research Service, Food Surveys Research Group Web site. Beltsville, MD: U.S. Department of Agriculture ARS, Beltsville Human Nutrition Research Center, Food Surveys Research Group and Hyattsville, MD: U.S. Department of Health and Human Services CfDCaP, National Center for Health Statistics. What We Eat in America, NHANES 2005-2006 [cited 200930 Jul]. Available from: http://www. cdc.gov/nchs/about/major/nhanes/nhanes2003-2004/dr1tot_c.xpt.

33. Popkin BM, Siega-Riz AM, Haines PS, Jahns L. Where's the fat? Trends in U.S. diets 1965-1996. Prev Med. 2001;32:245-54.

34. Nielsen SJ, Popkin BM. Changes in beverage intake between 1977 and 2001. Am J Prev Med. 2004;27:205-10.

35. Popkin BM, Haines PS, Siega-riz AM. Dietary patterns and trends in the United States: the UNC-CH approach. Appetite. 1999;32:8-14.

36. Stata Corp. STATA V. College Station (TX): Stata Corp.; 2009.

37. French SA, Story M, Fulkerson JA, Gerlach AF. Food environment in secondary schools: a la carte, vending machines, and food policies and practices. Am J Public Health. 2003;93:1161-7.

38. Diliberti N, Bordi PL, Conklin MT, Roe LS, Rolls BJ. Increased portion size leads to increased energy intake in a restaurant meal. Obes Res. 2004;12:562-8.

39. Beydoun MA, Powell LM, Chen X, Wang Y. Food Prices Are Associated with Dietary Quality, Fast Food Consumption, and Body Mass Index among U.S. Children and Adolescents. J Nutr. 2011;141:304-11.

40. Gentilcore D, Chaikomin R, Jones KL, Russo A, Feinle-Bisset C, Wishart JM, Rayner CK, Horowitz M. Effects of fat on gastric emptying of and the glycemic, insulin, and incretin responses to a carbohydrate meal in type 2 diabetes. J Clin Endocrinol Metab. 2006;91:2062-7.

41. Ma J, Stevens JE, Cukier K, Maddox AF, Wishart JM, Jones KL, Clifton PM, Horowitz M, Rayner CK. Effects of a protein preload on gastric emptying, glycemia, and gut hormones after a carbohydrate meal in diet-controlled type 2 diabetes. Diabetes Care. 2009;32:1600-2.

42. Rolls BJ, Roe LS, Meengs JS. Salad and satiety: energy density and portion size of a first-course salad affect energy intake at lunch. J Am Diet Assoc. 2004;104:1570-6.

43. Bowen J, Noakes M, Trenerry C, Clifton PM. Energy intake, ghrelin, and cholecystokinin after different carbohydrate and protein preloads in overweight men. J Clin Endocrinol Metab. 2006;91:1477-83.

44. Flood JE, Roe LS, Rolls BJ. The effect of increased beverage portion size on energy intake at a meal. J Am Diet Assoc. 2006;106:1984-90; discussion 90-1.

45. Wansink B. Mindless eating: why we eat more than we think. New York: Bantam-Dell; 2006.

46. Rolls BJ, Roe LS, Meengs JS. Larger portion sizes lead to a sustained increase in energy intake over 2 days. J Am Diet Assoc. 2006;106:543-9.

47. Perloff BP, Rizek RL, Haytowitz DB, Reid PR. Dietary intake methodology. II. USDA's Nutrient Data Base for Nationwide Dietary Intake Surveys. J Nutr. 1990;120 Suppl 11:1530-4.

48. Bandini LG, Schoeller DA, Cyr HN, Dietz WH. Validity of reported energy intake in obese and nonobese adolescents. Am J Clin Nutr. 1990;52:421-5.

49. Young LR, Nestle MS. Portion sizes in dietary assessment: issues and policy implications. Nutr Rev. 1995;53:149-58.

50. Harnack L, Steffen L, Arnett DK, Gao S, Luepker RV. Accuracy of estimation of large food portions. J Am Diet Assoc. 2004;104:804-6.

51. Heitmann BL, Lissner L, Osler M. Do we eat less fat, or just report so? Int J Obes Relat Metab Disord. 2000;24:435-42.

52. Champagne CM, Baker NB, DeLany JP, Harsha DW, Bray GA. Assessment of energy intake underreporting by doubly labeled water and observations on reported nutrient intakes in children. J Am Diet Assoc. 1998;98:426-33.

53. Waling MU, Larsson CL. Energy intake of Swedish overweight and obese children is underestimated using a diet history interview. J Nutr. 2009;139:522-7. 